\title{
Experimental Study on Properties of Cement-based Grouting Materials under High Geo-temperature Condition
}

\author{
Yongqiang Yu ${ }^{1,2}$, Tianxiang Peng ${ }^{2}$, Lidan Fan ${ }^{2,3, *}$, Jiyun Zhang ${ }^{2}$ and MengYang ${ }^{2}$ \\ ${ }^{1}$ Henan Key Laboratory of Underground Engineering Disaster Prevention, Henan Polytechnic University, Jiaozuo 454003, China \\ ${ }^{2}$ School of Civil Engineering, Henan Polytechnic University, Jiaozuo 454003, China \\ ${ }^{3}$ International Joint Research Laboratory of Henan Province for Underground Space Development and Disaster Prevention, Henan \\ Polytechnic University, Jiaozuo 454003, China
}

Received 13 March 2021; Accepted 8 May 2021

\begin{abstract}
The high geo-temperature is becoming a more common geological condition in tunnel and mining engineering, it is urgent to prepare grouting materials possessing preferable properties to adapt to the high geothermal environment. To develop an appropriate cement-based grouting material through incorporating fly ash, slag powder and superplasticizer, its properties in the simulated high geothermal environment in the background of Gaoligong Mountain tunnel in China were investigated. The orthogonal experiment was applied and the grouting material properties were contrastively studied at $40{ }^{\circ} \mathrm{C}$ and $20{ }^{\circ} \mathrm{C}$, respectively. Meanwhile, the optimal formulation for grouting materials was determined by the matrix analysis. Results show that compared with that at $20{ }^{\circ} \mathrm{C}$, the setting time of the grouting material at $40{ }^{\circ} \mathrm{C}$ is shorter, as well as the bleeding rate and compressive strength are superior, which is very conducive to grouting. The water-cement ratio of the optimal grouting material is 0.6 . In the composition of the optimal grouting material, the superplasticizer is $0.15 \%$ and the slag powder content is $30 \%$. The conclusions provide a significant reference to the application of the cement-based grouting material in the similar geothermal environment.
\end{abstract}

Keywords: High geo-temperature, Cement-based grouting, Fly ash, Slag powder, Orthogonal experiment

\section{Introduction}

With the development of transportation engineering and the exploitation of coal resources, the construction of long tunnels and deep mines has become a trend. The deeper the tunnels and mines, the more complicated the geological environment, such as broken surrounding rock and tunnel water gushing, which seriously affects the safety of the project [1]. Water inrush in underground construction refers to the massive gushing of groundwater from the pores or fissures of the geological body on the face of the tunnel, which brings trouble to the construction. Water and mud burst refers to the combination of groundwater and geological materials under the action of high-head groundwater in the face of the tunnel. The phenomenon of burying an already dug tunnel is also called underground debris flow or underground debris flow.

High geo-temperature (HGT) is also an inevitable geological hazard in tunnel engineering and mine engineering [2]. For example, during the construction of the Gotthard Tunnel in Switzerland, the temperature of the tunnel was as high as $45^{\circ} \mathrm{C}$ [3]. The maximum depth of Gaoligong Mountion Tunnel of Dali-Ruili Railway in China was $1155 \mathrm{~m}$, and the highest geo-temperature was $45^{\circ} \mathrm{C}$ [4]. The geo-temperature of Xuzhou Sanhejian Coal Mine at the level of $-980 \mathrm{~m}$ was $46.8^{\circ} \mathrm{C}$ [5]. The high-temperature and high-humidity environment of tunnel construction not only endangers the health and safety of operators, but also reduces labor productivity, or even makes construction impossible, which deteriorates the working conditions of

*E-mail address: 517635870@qq.com

ISSN: 1791-2377 @ 2021 School of Science, IHU. All rights reserved.

doi:10.25103/jestr.142.18 mechanical equipment, reduces efficiency, and increases failures [6-7]. At the same time, chemical substances in high-temperature water corrosion also affects the quality of the tunnel structure. China began to conduct geothermal research in the 1950 s and 1960 s, but it was mainly used for energy development. There are some studies on mine thermal hazards, but the system is relatively poor. In the past construction of railway tunnels, due to its shallow buried depth, the original rock temperature in the tunnel was not very high, and no serious heat damage was encountered. Therefore, there is currently no systematic theory and mature governance experience.

During the engineering construction, there are many methods in governance of the surrounding rock and tunnel water gushing, and grouting technology is among them. Grouting water blocking is the use of mechanical highpressure power to inject water-soluble polyurethane chemical grouting materials into concrete cracks. When the grout meets the moisture in the concrete cracks, it will quickly disperse, emulsify, expand, and consolidate, so that the consolidated elastomer fills the concrete. All cracks completely block the water flow outside the concrete structure to achieve the purpose of water stop and leakage. However, HGT in tunnels and mines often reduces the management efficiency of these methods. This hazard not only destroys the working environment, but also causes problems such as the decrease in the adhesion of shotcrete [8-9], the drop in the pull-out resistance of the anchor rod [10], and the cracking of the concrete linings. In addition, HGT also affects the choice of construction materials including grouting materials [11-12]. As the traditional grouting materials are increasingly difficult to meet 
engineering demand, the research of suitable grouting materials for underground engineering with high geotemperature has become a top priority.

The abnormal geothermal phenomenon causes deterioration of the working performance, physical mechanics and durability of the tunnel concrete lining, which affects the safety and service life of the tunnel structure. Therefore, to ensure the safe construction of tunnels with high ground temperature and risk of water inrush, it is of great significance to prepare tunnel water inrush grouting materials with preferred characteristics to adapt to high geothermal environment.

\section{State of the Art}

Selecting an appropriate grouting material is an important step for the success of grouting projects. The choice of grout ingredients and the change of their proportions have great effect on the properties of cement-based grouting materials (CBGM). Li et al. studied rheological and mechanical properties of CBGM containing different amounts of blast furnace slag and fly ash at $23 \pm 3{ }^{\circ} \mathrm{C}$, and they concluded that the fluidity, spreading ability and stability of CBGM were improved by these mineral admixtures [13]. Sha et al. designed the cement-based grouts admixed with fly ash, bentonite, superplasticizer and sodium silicate to improve of grouting materials properties at room temperature, and they found that the fly ash could enhance the fluidity and spread ability of CBGM [14].

In addition, the effect of temperature on CBGM is also the key to the function of grouting material under high geothermal environment. In previous studies, scholars have conducted experiments on cement-based materials at different temperatures. Narmluk and Nawa found that the hydration was delayed in the early stage and accelerated in the later stage on account of fly ash at $20{ }^{\circ} \mathrm{C}$ and $35^{\circ} \mathrm{C}$, while the hydration was delayed in all stages when fly ash was used in a higher replacement ratio at $50^{\circ} \mathrm{C}$ [15]. Sun et al. studied the effect of fly ash microspheres on cement hydration and microstructure at three constant temperatures and concluded that the fly ash microspheres mainly played a physical role at room temperature while the pozzolanic activity of fly ash microspheres could be significantly activated by increasing the curing temperature [16]. Wang and Liu introduced the effects of different curing temperatures on the hydration process, pore structure changes and compressive strength development of fly ashcement grouting materials [17]. Chen et al. found that slag powder played an important role in improving the fluidity of CBGM and avoided the cement setting and hardening prematurely at high temperatures [18]. Aziz et al. also found that the compressive strength of cement pastes mixed with slag at high curing temperature was higher than that at standard temperature [19]. These research findings showed the effect of temperature on the properties of cement-based materials from a micro or macro perspective, which were the motivation for this study.

The optimal formulation of CBGM means that the grout possesses preferable properties under some particular conditions. Many scholars have conducted research on the formulations of composite cement-based grouting materials at ambient temperature. Zhang et al. proposed a new type of grouting material for the reinforcement of large-scale floor cracks by producing 12 sets of samples and fully comparatively analysing the physicochemical properties [20]. Liu et al. developed a new kind of powder geopolymer grouting material originated from slag powder and fly ash for filling void beneath cement pavement slab, and obtained the optimal formulation [21]. Sha et al. proposed a kind of microfine cement-based grout for the anti-seepage and reinforcement applications, which has advantages such as good viscous behavior, fluidity and stability [22]. Zhang et al. developed the optimal formulation of a new cementbentonite grouting material mixed with meta-aluminate and lignin to fill karst caverns [23].

However, there are few studies on the formulation of CBGM suitable for high geo-temperature environments, and even fewer studies on grouting materials mixed with fly ash in this environment. Therefore, the properties of CBGM mixed with fly ash and slag powder at higher curing temperature were studied by simulating the high geothermal environment of Gaoligong Mountain tunnel. At first, the experimental schemes of CBGM such as the contents of cement, fly ash and slag powder were designed by orthogonal test method. Also, the setting time, viscosity, bleeding rate and compressive strength of different formulations of CBGM at $20^{\circ} \mathrm{C}$ and $40{ }^{\circ} \mathrm{C}$ were tested. At last, the effect of different factors on properties of CBGM was analysed by the range analysis method, and the optimal formulation suitable for high geo-temperature tunnel at about $40{ }^{\circ} \mathrm{C}$ was obtained. This study could provide an alternative selection of grouting materials in the similar practice.

The rest of this study is organized as follows. Section 3 gives the orthogonal experimental design and experimental procedure. Section 4 describes the experimental results, and finally, the conclusions are summarized in Section 5.

\section{Methodology}

\subsection{Orthogonal experimental design}

The orthogonal experimental design (OED) is a method to select representative points from full factorial experiment in a way, and the points have the characteristics of uniform dispersion, symmetry and comparability [24]. The better technical condition or optimal formulations can be found with the least number of experiments. Thus, it has been widely applied in experimental research by virtue of reducing the number of required experiments.

The OED was selected to help analyse the effect of key parameters on the properties of CBGM. According to the previous research on water cement ratio and bentonite content of grouting materials, it could be concluded that a relatively stable grout can be obtained in the following combination: 0.6 of the water-cement ratio (W-C) and $0 \%$ of the bentonite, 0.8 of $\mathrm{W}-\mathrm{C}$ and $3 \%$ of the bentonite, 1 of $\mathrm{W}-\mathrm{C}$ and $6 \%$ of the bentonite, 1.2 of W-C and $9 \%$ of the bentonite. Then fly ash and slag powder were used to replace cement with the same quality, and superplasticizer was mixed to increase the fluidity. Thus, an orthogonal design of $\mathrm{L}_{16}\left(4^{5}\right)$ was used in the experiment. The four factors were $\mathrm{W}-\mathrm{C}$ and bentonite content A, superplasticizer content B, fly ash content $\mathrm{C}$ and slag powder content $\mathrm{D}$, and each factor was examined at four values. The factors and the experimental cases are shown in Tables 1 and 2, respectively.

Range analysis was applied for the index evaluation of grouting materials in this paper, which is simple and intuitive. The effect of various factors on the properties of CBGM was analysed by range analysis method. Range value (R) can be calculated as: 


$$
R_{i}=\max \left(k_{i j}\right)-\min \left(k_{i j}\right)
$$

where $j$ represents the factor levels, from 1 to $4 ; i$ is the factor $\mathrm{A}, \mathrm{B}, \mathrm{C}, \mathrm{D} ; R_{i}$ is defined as the range value of factor $j$; $k_{i j}$ indicates the mean value of the corresponding indices of factor $i$ at all level $j$. The larger the range value of a factor, the greater the effect of the factors on the properties indices. That is to say, this factor is more sensitive to the results.

Table 1. Values of factors for orthogonal experiment.

\begin{tabular}{c|c|c|c|c}
\hline \multirow{2}{*}{ Levels } & \multicolumn{4}{|c}{ Levels of factors } \\
\cline { 2 - 5 } & $\mathbf{A}$ & $\mathbf{B}$ & $\mathbf{C}$ & D \\
\hline 1 & $0.6 / 0 \%$ & $0 \%$ & $0 \%$ & $0 \%$ \\
2 & $0.8 / 3 \%$ & $0.1 \%$ & $20 \%$ & $30 \%$ \\
3 & $1.0 / 6 \%$ & $0.15 \%$ & $30 \%$ & $40 \%$ \\
4 & $1.2 / 9 \%$ & $0.2 \%$ & $40 \%$ & $50 \%$ \\
\hline
\end{tabular}

Table 2. The experimental cases of orthogonal design.

\begin{tabular}{c|c|c|c|c}
\hline \multirow{2}{*}{ Number } & \multicolumn{4}{|c}{ Column number } \\
\cline { 2 - 5 } & $\mathbf{A}$ & $\mathbf{B}$ & $\mathbf{C}$ & $\mathbf{D}$ \\
\hline 1 & $0.6 / 0 \%$ & $0 \%$ & $0 \%$ & $0 \%$ \\
2 & $0.6 / 0 \%$ & $0.1 \%$ & $20 \%$ & $30 \%$ \\
3 & $0.6 / 0 \%$ & $0.15 \%$ & $30 \%$ & $40 \%$ \\
4 & $0.6 / 0 \%$ & $0.2 \%$ & $40 \%$ & $50 \%$ \\
5 & $0.8 / 3 \%$ & $0 \%$ & $20 \%$ & $40 \%$ \\
6 & $0.8 / 3 \%$ & $0.1 \%$ & $0 \%$ & $50 \%$ \\
7 & $0.8 / 3 \%$ & $0.15 \%$ & $40 \%$ & $0 \%$ \\
8 & $0.8 / 3 \%$ & $0.2 \%$ & $30 \%$ & $30 \%$ \\
9 & $1.0 / 6 \%$ & $0 \%$ & $30 \%$ & $50 \%$ \\
10 & $1.0 / 6 \%$ & $0.1 \%$ & $40 \%$ & $40 \%$ \\
11 & $1.0 / 6 \%$ & $0.15 \%$ & $0 \%$ & $30 \%$ \\
12 & $1.0 / 6 \%$ & $0.2 \%$ & $20 \%$ & $0 \%$ \\
13 & $1.2 / 9 \%$ & $0 \%$ & $40 \%$ & $30 \%$ \\
14 & $1.2 / 9 \%$ & $0.1 \%$ & $30 \%$ & $0 \%$ \\
15 & $1.2 / 9 \%$ & $0.15 \%$ & $20 \%$ & $50 \%$ \\
16 & $1.2 / 9 \%$ & $0.2 \%$ & $0 \%$ & $40 \%$ \\
\hline
\end{tabular}

However, the range analysis was insufficient for dealing with multi-index orthogonal experiment, so the matrix analysis method was used to calculate the weight of each factor on the test results to determine the optimal formulation for grouting materials [25]. In this method, a three-layer structure model based on data structure of the orthogonal experiment was established, as shown in Table 3. The three layers represented evaluation index, factor, and the level of OED, respectively. Then the corresponding matrix was established according to the data of each layer.

\subsection{Raw materials}

The 42.5 ordinary Portland cement, originating from Jiaozuo Zhongjing Cement Co. Ltd in China, was used as one of the most essential composition for CBGM. The specific chemical constituents are shown in Table 4.

Table 4. The specific chemical constituents of cement.

\begin{tabular}{c|c|c|c|c|c}
\hline Ingredient & $\mathbf{M g O}$ & $\mathbf{S O}_{3}$ & $\mathbf{C l}^{-}$ & $\mathbf{N a}_{2} \mathbf{O}$ & Loss on \\
\hline Content (\%) & 3.04 & 2.64 & 0.02 & 0.31 & 3.36 \\
\hline
\end{tabular}

The bentonite was obtained from Xinyang Shuangcheng factory in China. The main component of bentonite is montmorillonite, which has strong adsorption and can improve the stability of the grouting liquid.

The Polycarboxylate superplasticizer was produced by Zhengzhou Meiya Co. Ltd. in China. It is a copolymer with carboxyl group in molecular structure, possessing high water-reducing rate.

Table 3. Data structure model of the orthogonal experiment.

\begin{tabular}{|c|c|c|c|c|c|c|c|c|c|}
\hline Layer 1 & \multicolumn{9}{|c|}{ Evaluation index } \\
\hline Layer 2 & \multicolumn{3}{|c|}{ Factor $A_{1}$} & \multicolumn{3}{|c|}{ Factor $\mathrm{A}_{2}$} & \multicolumn{3}{|c|}{ Factor $\mathrm{A}_{\mathrm{r}}$} \\
\hline Layer 3 & $\mathrm{~A}_{11}$ & $A_{12}$ & $\mathrm{~A}_{1 \mathrm{~m}}$ & $\mathrm{~A}_{21}$ & $\mathrm{~A}_{22}$ & $\mathrm{~A}_{2 \mathrm{~m}}$ & $\mathrm{~A}_{\mathrm{r} 1}$ & $\mathrm{~A}_{\mathrm{r} 2}$ & $\mathrm{~A}_{\mathrm{rm}}$ \\
\hline
\end{tabular}

Two mineral admixtures were added to the grouting material. Class II fly ash was purchased from Jiaozuo Power Plant in China. And it can improve the microstructure of CBGM due to its morphologic effect. Slag powder, produced by Jiaozuo Danyang Cement Plant in China, is the finely ground powder of blast furnace slag.

\subsection{Experimental procedure}

The grouting materials were prepared according to the proportions of various components, which included cement, bentonite, fly ash, slag powder and superplasticizer. At first, the required raw materials were weighed and added to the mixing in the appropriate order based on orthogonal design. Then they were stirred with the cement paste mixer to obtain the grout. Then the setting time, viscosity, bleeding rate of the grout and compressive strength of hardened past were tested.

To test the setting time at high temperatures, the water bath protector was self-designed referring to the standard mold. The self-designed device was mainly composed of three parts, namely the bottom plate, the mold for holding grouting and the water bath protector, as shown in Fig. 1.

The prepared grout was poured into the water bath protector, and then was put into temperature-controlled waterbath, namely $20{ }^{\circ} \mathrm{C}$ and $40{ }^{\circ} \mathrm{C}$. And the test procedure was carried out by referring to the Chinese standard GB/T1346-2011.
To test the viscosity of CBGM, the standard funnel viscometer, measuring cup, and beaker were used. According to the measuring principle of the standard funnel viscometer, at first, the nozzle of the thin tube at the bottom of the funnel was plugged by hand tightly. After that, $200 \mathrm{ml}$ of the grout from one part of the measuring cup was injected into the funnel through the filter, and then $500 \mathrm{ml}$ of the grout from the other part of measuring cup was injected into the funnel. Then the $500 \mathrm{ml}$ measuring cup was put under the funnel, the hand was leaved away from the lower mouth of the funnel thin tube, and the stopwatch was started at the same time. At last, the time it took for the $500 \mathrm{ml}$ grout flowing from the funnel was recorded. This time was used to represent the viscosity of the grout.

The measuring cylinders and beakers were used to evaluate the bleeding rate of CBGM. The prepared grout was poured into a $250 \mathrm{ml}$ measuring cylinder, and the total volume $V_{1}$ was recorded. Meanwhile the top of the measuring cylinder was sealed with plastic wrap. Then it was put back immediately in waterbath of $20{ }^{\circ} \mathrm{C}$ and $40{ }^{\circ} \mathrm{C}$ respectively. After being kept in the waterbath for $2 \mathrm{~h}$, the water separation volume $V_{2}$ was recorded and the water bleeding rate $\alpha=V_{2} / V_{1}$ was calculated.

The method for determining the compressive strength of CBGM referred to the Chinese standard. The prepared grout was poured into the test mold and put into a curing box at $20{ }^{\circ} \mathrm{C}$ and $40{ }^{\circ} \mathrm{C}$ for $24 \mathrm{~h}$. Then the test block without mold 
was maintained to $3 \mathrm{~d}, 7 \mathrm{~d}, 14 \mathrm{~d}$ and $28 \mathrm{~d}$. Finally, the compressive strength was measured by a universal testing machine.

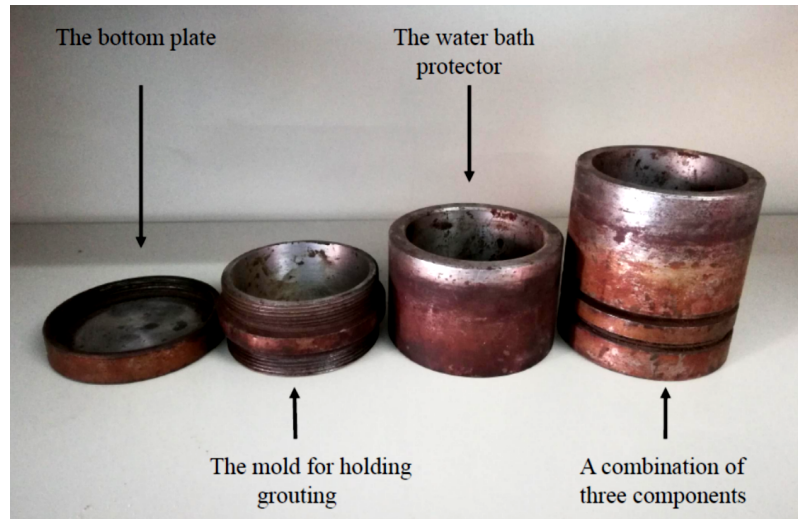

Fig. 1. Illustration of the self-designed mold for testing setting time.

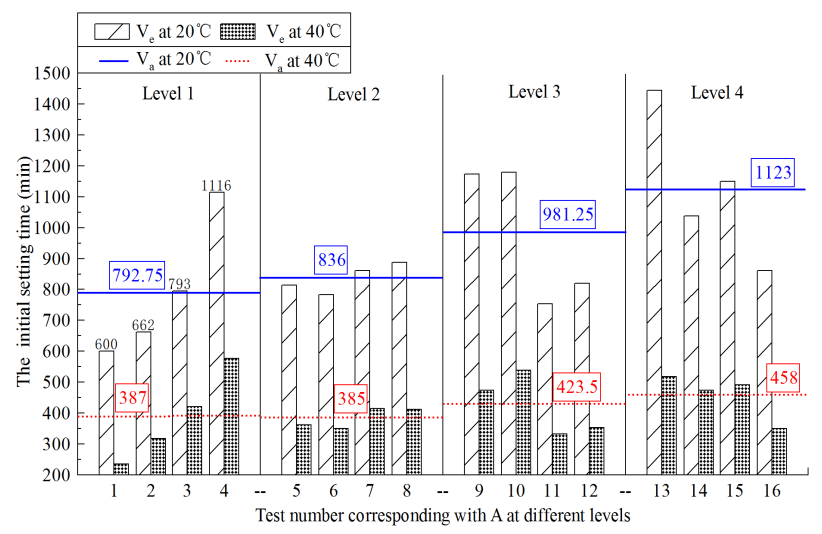

(a) Values of the initial setting time for factor $\mathrm{A}$

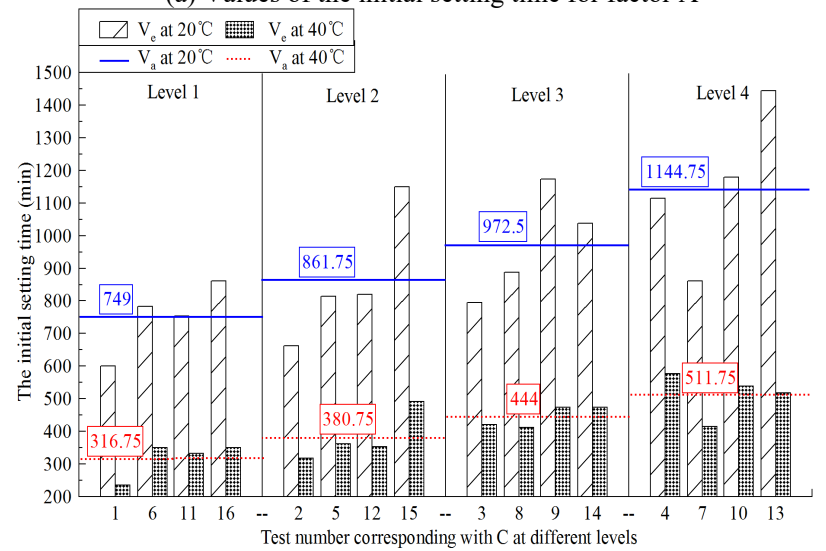

(c) Values of the initial setting time for factor $\mathrm{C}$

\section{Results and discussion}

4.1 Range analysis on the setting time

The experimental original results and the processed results of the initial setting time are shown in Fig. 2. According to the experimental results, the initial setting time at $20^{\circ} \mathrm{C}$ and $40{ }^{\circ} \mathrm{C}$ was analysed by range analysis, as shown in Table 5 . Take the initial setting time as an example in Fig. 2(a), the experimental values of the initial setting time for factor $\mathrm{A}$ at all level 1 (that is, the experimental values of the initial setting time at $0.6 / 0 \%$ ) are $600 \mathrm{~min}, 662 \mathrm{~min}, 793 \mathrm{~min}$, and 1116 min. Thus, $k_{\mathrm{A} 1}=(600+662+793+1116) / 4=792.75$. In this way, $k_{\mathrm{A} 2}=836, k_{\mathrm{A} 3}=981.25$ and $k_{\mathrm{A} 4}=1123$ are obtained. The range value of factor $A$ is obtained by calculating the difference between the maximum and minimum values $k_{A j}$, $R_{A}=1123-792.75=330.25$, which is shown in Table 5 .

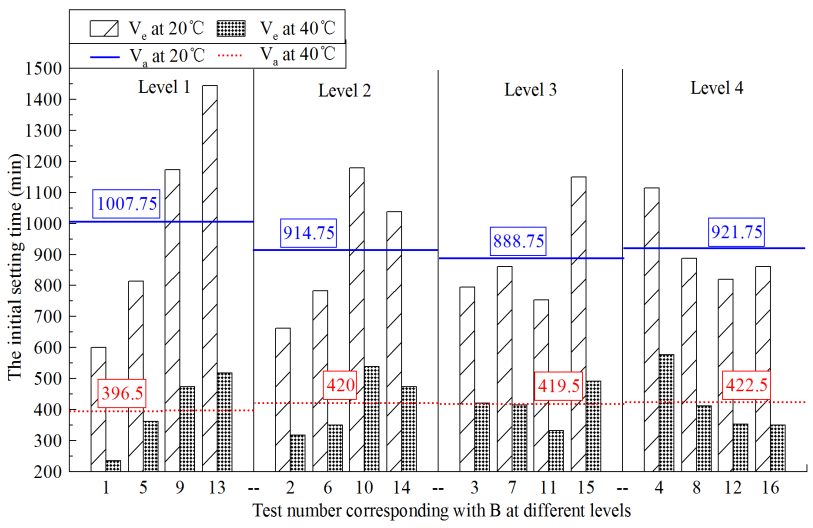

(b) Values of the initial setting time for factor B

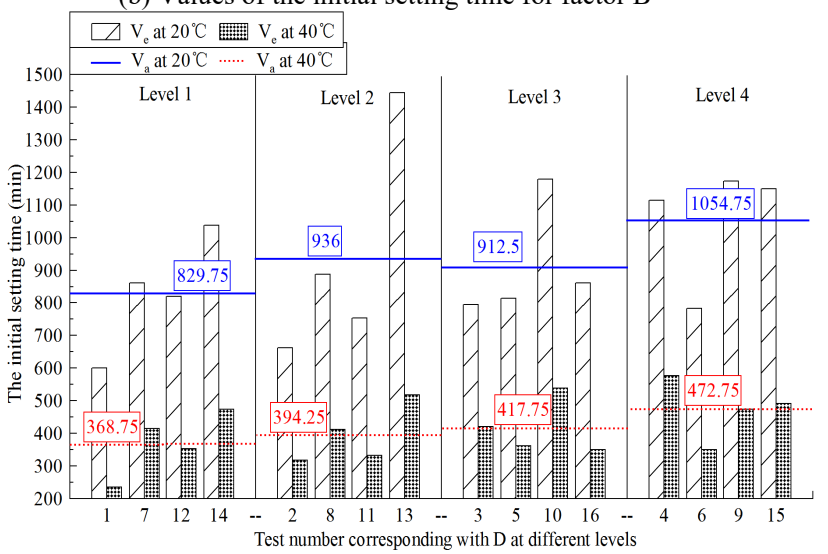

(d) Values of the initial setting time for factor $\mathrm{D}$

Fig. 2. The diagram of experimental values and average values of initial setting time $\left(V_{e}\right.$ represents experimental value at $20^{\circ} \mathrm{C}$ and $40{ }^{\circ} \mathrm{C} . V_{a}$ represents average value at $20^{\circ} \mathrm{C}$ and $40^{\circ} \mathrm{C}$ ).

Table 5. Range analysis on initial setting time at $20^{\circ} \mathrm{C}$ and $40^{\circ} \mathrm{C}$.

\begin{tabular}{c|c|c|c|c|c|c|c|c}
\hline T $\left({ }^{\circ} \mathbf{C}\right)$ & \multicolumn{9}{c}{$\mathbf{2 0}$} & \multicolumn{3}{c}{$\mathbf{4 0}$} \\
\hline Levels & $\mathbf{A}$ & $\mathbf{B}$ & $\mathbf{C}$ & $\mathbf{D}$ & $\mathbf{A}$ & $\mathbf{B}$ & $\mathbf{C}$ & $\mathbf{D}$ \\
\hline 1 & 792.75 & 1007.75 & 749.00 & 829.75 & 387.00 & 396.50 & 316.75 & 368.75 \\
\hline 2 & 836.00 & 914.75 & 861.75 & 936.00 & 385.00 & 420.00 & 380.75 & 394.25 \\
\hline 3 & 981.25 & 888.75 & 972.50 & 912.50 & 423.50 & 419.50 & 444.00 & 417.75 \\
\hline 4 & 1123.00 & 921.75 & 1144.75 & 1049.75 & 458.00 & 422.50 & 511.75 & 472.5 \\
\hline Range & 330.25 & 119.00 & 395.75 & 220.00 & 73.00 & 26.25 & 195.00 & 103.75 \\
\hline $\begin{array}{c}\text { Optimizing } \\
\text { scheme }\end{array}$ & A1 & B 3 & C1 & D1 & A2 & B1 & C1 & D1 \\
\hline
\end{tabular}

From the value of the range, the greatest effect on the initial setting time the grout at $20{ }^{\circ} \mathrm{C}$ is the content of fly ash, followed by water cement ratio (For the convenience of description, only W-C will be mentioned below, instead of mentioning water-cement ratio and bentonite content), slag powder content and superplasticizer content. The results indicated that fly ash played a major role in controlling the setting time of grouting at $20^{\circ} \mathrm{C}$, while fly ash was more 
influential than slag powder at $40{ }^{\circ} \mathrm{C}$. The optimum formulation at $20{ }^{\circ} \mathrm{C}$ and $40{ }^{\circ} \mathrm{C}$ from Table 5 was $\mathrm{A} 1 / \mathrm{B} 3 / \mathrm{C} 1 / \mathrm{D} 1$ and $\mathrm{A} 2 / \mathrm{B} 1 / \mathrm{C} 1 / \mathrm{D} 1$, respectively.

To further intuitively analyse the effect of various factors on the setting time (Fig. 3), the trend chart of the effects of various factors on the initial setting time at $20^{\circ} \mathrm{C}$ and $40{ }^{\circ} \mathrm{C}$ was drawn from the values in Table 5 . It can be seen that the initial setting time of $\mathrm{CBGM}$ at $20^{\circ} \mathrm{C}$ and $40^{\circ} \mathrm{C}$ increased with W-C, fly ash and slag powder content in different degrees, respectively. However, the initial setting time of $\mathrm{CBGM}$ at $20^{\circ} \mathrm{C}$ firstly was shortened and then extended with the increase of superplasticizer content. The results showed that a small amount of superplasticizer could accelerate the solidification of the grout at $20{ }^{\circ} \mathrm{C}$. When its content was in the range of $0.1-0.2 \%$, the effect on the initial setting time changed slightly. While the initial setting time of CBGM at $40{ }^{\circ} \mathrm{C}$ was extended slightly with the increase of superplasticizer content. This may be because the water reducer molecules become active and adsorbed on the surface of cement particles, which would inhibit the hydration reaction of the grout. In addition, the setting time of different formulations of $\mathrm{CBGM}$ at $40{ }^{\circ} \mathrm{C}$ was significantly shorter than that at $20^{\circ} \mathrm{C}$, which showed that temperature had great effect on the initial setting time.

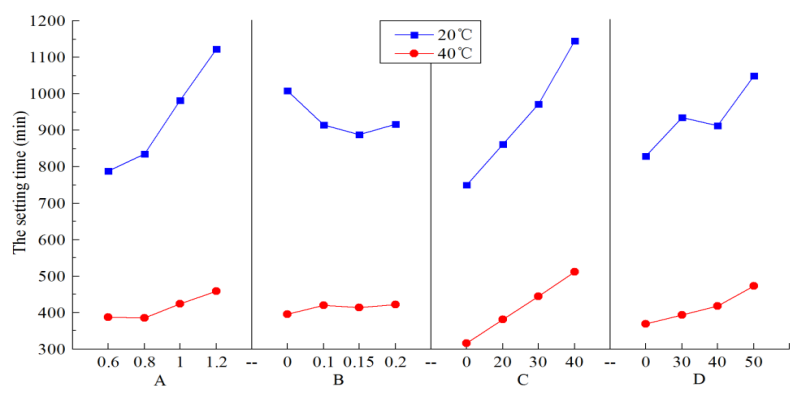

Fig. 3. Response curve of initial setting time varying with factors, $\mathrm{W}-\mathrm{C}$ (A), superplasticizer content $(\mathrm{B} / \%)$, fly ash content $(\mathrm{C} / \%)$, slag powder content $(\mathrm{D} / \%)$.

\subsection{Range analysis of viscosity}

Range analysis of the viscosity of CBGM at $20^{\circ} \mathrm{C}$ and $40{ }^{\circ} \mathrm{C}$ was carried out and the results are listed in Table 6 . The significance of these four factors followed the order based on the Range: $\mathrm{A}>\mathrm{B}>\mathrm{C}>\mathrm{D}\left(20^{\circ} \mathrm{C}\right)$ and $\mathrm{A}>\mathrm{C}>\mathrm{B}>\mathrm{D}$ $\left(40{ }^{\circ} \mathrm{C}\right)$, suggesting that $\mathrm{W}-\mathrm{C}$ was still the most significant factor for the viscosity. Besides, the optimum formulation for reducing viscosity was A4/B4/C4/D4, namely $\mathrm{W}-\mathrm{C}$ of
1.2 , the superplasticizer content of $0.2 \%$, the fly ash content of $40 \%$, and the slag powder content of $50 \%$.

Fig. 4 shows that the effect of various factors on the viscosity at $20{ }^{\circ} \mathrm{C}$ and $40{ }^{\circ} \mathrm{C}$. The viscosity decreased with the increasing of four factors (A, B, C \& D) generally. Besides, the effect of various factors on the viscosity of $\mathrm{CBGM}$ at $40{ }^{\circ} \mathrm{C}$ was greater than that at $20{ }^{\circ} \mathrm{C}$, which indicated that the admixture and the additive was more conducive to decrease the viscosity of the grout when temperature rose. In addition, it could be known that the viscosity of grouting with low W-C and without superplasticizer, fly ash and slag powder at $40^{\circ} \mathrm{C}$ was higher than that at $20^{\circ} \mathrm{C}$, suggesting that when the admixture and additive were not added, the hydration rate of the cement increased with the rising of temperature, which leaded to the accelerated flocculation form, manifesting increasing viscosity.

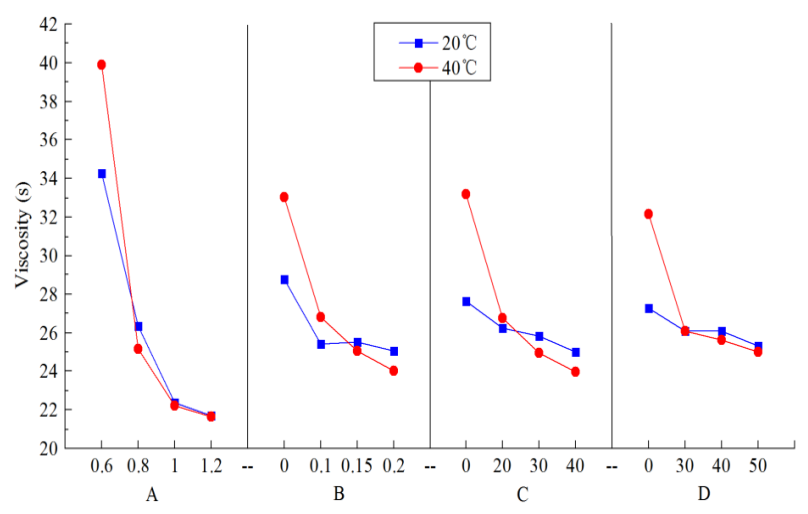

Fig. 4. Response curve of viscosity varying with factors, W-C (A), superplasticizer content $(\mathrm{B} / \%)$, fly ash content $(\mathrm{C} / \%)$, slag powder content $(\mathrm{D} / \%)$.

The viscosity of the grout containing the fly ash and slag powder was greatly decreased at $40{ }^{\circ} \mathrm{C}$, which could be interpreted that the increase of temperature accelerated the movement of fly ash and mineral powder particles, and thus made the viscosity decrease faster. Meanwhile, the reason why the viscosity of the grout decreased faster with the increase of superplasticizer content at $40{ }^{\circ} \mathrm{C}$ was that the increase of temperature enhanced the adsorption capacity of the superplasticizer and formed a more stable hydration film, which played a good lubricating role and reduced the viscosity of the grout.

Table 6. Range analysis of viscosity at $20^{\circ} \mathrm{C}$ and $40{ }^{\circ} \mathrm{C}$.

\begin{tabular}{c|c|c|c|c|c|c|c|c}
\hline T $\left({ }^{\circ} \mathbf{C}\right)$ & \multicolumn{3}{|c|}{$\mathbf{2 0}$} & \multicolumn{3}{c}{$\mathbf{4 0}$} \\
\hline Levels & $\mathbf{A}$ & $\mathbf{B}$ & $\mathbf{C}$ & $\mathbf{D}$ & $\mathbf{A}$ & $\mathbf{B}$ & $\mathbf{C}$ \\
\hline 1 & 34.255 & 28.735 & 27.635 & 27.24 & 39.888 & 33.01 & 33.203 & 32.17 \\
\hline 2 & 26.34 & 25.415 & 26.252 & 26.075 & 25.155 & 26.822 & 26.73 \\
\hline 3 & 22.39 & 25.495 & 25.828 & 26.087 & 22.197 & 25.03 & 24.97 & 25.695 \\
\hline 4 & 21.723 & 25.063 & 24.992 & 25.305 & 21.623 & 24 & 23.96 & 24.988 \\
\hline Range & 12.523 & 3.672 & 2.643 & 1.935 & 18.265 & 9.01 & 9.243 & 7.182 \\
\hline $\begin{array}{c}\text { Optimizing } \\
\text { scheme }\end{array}$ & A4 & B4 & C4 & D4 & A4 & B4 & D4 \\
\hline
\end{tabular}

\subsection{Range analysis of bleeding rate}

Table 7 shows that the effect of various factors on the bleeding rate at $20^{\circ} \mathrm{C}$ and $40{ }^{\circ} \mathrm{C}$ based on the range analysis. For the effect degree at $20{ }^{\circ} \mathrm{C}$, the factors affecting the bleeding rate were $\mathrm{W}-\mathrm{C}$, fly ash, superplasticizer and slag powder. And for the effect degree at $40{ }^{\circ} \mathrm{C}$, the factors affecting the bleeding rate were $\mathrm{W}-\mathrm{C}$, fly ash, slag powder and superplasticizer. From these results, it could be obtained that $\mathrm{W}-\mathrm{C}$ was the most important factor to the bleeding rate of CBGM. Besides, the best optimal combination for the bleeding rate of the grout at $20{ }^{\circ} \mathrm{C}$ and $40{ }^{\circ} \mathrm{C}$ were $\mathrm{A} 1 / \mathrm{B} 1 / \mathrm{C} 1 / \mathrm{D} 2$ (A of $0.6 \%, \mathrm{~B}$ of $0 \%, \mathrm{C}$ of $0 \%$, and $\mathrm{D}$ of $30 \%$ ) and $\mathrm{A} 1 / \mathrm{B} 3 / \mathrm{C} 1 / \mathrm{D} 1$ (A of $0.6 \%, \mathrm{~B}$ of $0.15 \%, \mathrm{C}$ of $0 \%$, and $\mathrm{D}$ of $0 \%$ ), respectively. 
Table 7. Range analysis of bleeding rate at $20^{\circ} \mathrm{C}$ and $40^{\circ} \mathrm{C}$.

\begin{tabular}{c|c|c|c|c|c|c|c|c}
\hline T $\left({ }^{\circ} \mathbf{C}\right)$ & \multicolumn{9}{c|}{$\mathbf{2 0}$} & \multicolumn{3}{|c}{$\mathbf{4 0}$} \\
\hline Levels & $\mathbf{A}$ & $\mathbf{B}$ & $\mathbf{C}$ & $\mathbf{D}$ & $\mathbf{A}$ & $\mathbf{B}$ & $\mathbf{C}$ & $\mathbf{D}$ \\
\hline 1 & 8.685 & 10.405 & 8.832 & 11.828 & 4.887 & 8.128 & 5.930 & 7.255 \\
\hline 2 & 8.965 & 11.732 & 11.345 & 10.732 & 7.900 & 8.215 & 7.313 & 8.440 \\
\hline 3 & 12.753 & 10.428 & 11.983 & 10.830 & 10.287 & 7.993 & 9.022 & 8.610 \\
\hline 4 & 14.102 & 11.940 & 12.345 & 11.115 & 10.767 & 9.508 & 11.578 & 9.537 \\
\hline $\begin{array}{c}\text { Range } \\
\text { schimizing }\end{array}$ & 5.417 & 1.535 & 3.513 & 1.096 & 5.880 & 1.515 & 5.648 & 2.282 \\
\hline
\end{tabular}

To further investigate the effect of various factors on the bleeding rate, the trend chart of the factors affecting the bleeding rate at $20^{\circ} \mathrm{C}$ and $40{ }^{\circ} \mathrm{C}$ are shown in Fig. 5 .

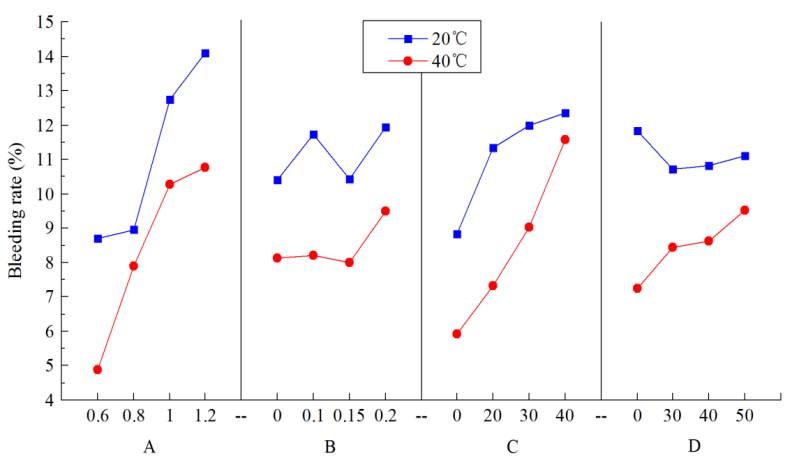

Fig. 5. Response curve of bleeding rate varying with factors, W-C (A), superplasticizer content $(\mathrm{B} / \%)$, fly ash content $(\mathrm{C} / \%)$, slag powder content $(\mathrm{D} / \%)$.

As can be seen from in Fig. 5, the bleeding rate of CBGM elevated gradually as W-C and the amount of fly ash increased. While with the increase of the superplasticizer, the bleeding rate of $\mathrm{CBGM}$ fluctuated at $20^{\circ} \mathrm{C}$, showing the characteristic of increasing first, decreasing and increasing again. Moreover, when the superplasticizer content was $0 \%$, $0.1 \%$ and $0.15 \%$ at $40{ }^{\circ} \mathrm{C}$, the bleeding rate did not change much, while when the content was $0.2 \%$, the bleeding rate of the grout obviously increased. And with the increasing content of slag powder, the bleeding rate of the grout decreased first and then increased at $20^{\circ} \mathrm{C}$, and increased all the time at $40{ }^{\circ} \mathrm{C}$. The results showed that the bleeding rate was the lowest when the slag powder content was $30 \%$ at $20{ }^{\circ} \mathrm{C}$. In addition, the bleeding rate at $40{ }^{\circ} \mathrm{C}$ was always lower than that at $20^{\circ} \mathrm{C}$ with the change of different factors.

\subsection{Range analysis of compressive strength}

To further intuitively investigate the effect of various factors on compressive strength at $20^{\circ} \mathrm{C}$ and $40{ }^{\circ} \mathrm{C}$, the trend chart was drawn. According to Fig. 6, with the increasing W-C and fly ash content, the compressive strength of every age at $20{ }^{\circ} \mathrm{C}$ and $40{ }^{\circ} \mathrm{C}$ decreased sharply, suggesting the $\mathrm{W}-\mathrm{C}$ and fly ash had a greater effect on compressive strength. With the increase of the superplasticizer and slag powder at $20^{\circ} \mathrm{C}$, the compressive strength of $3 \mathrm{~d}$ and $7 \mathrm{~d}$ decreased slowly, and the compressive strength increased first and then decreased at $14 \mathrm{~d}$ and $28 \mathrm{~d}$.

The compressive strength was maximum with the superplasticizer content of $0.1 \%$ and the slag powder content of $30 \%$, indicating that the superplasticizer and the slag powder had a good effect on the later strength at $20^{\circ} \mathrm{C}$. The compressive strength at $40{ }^{\circ} \mathrm{C}$ first increased and then decreased with the increase of the superplasticizer and slag powder, and the maximum was reached when the content of the superplasticizer and slag powder was $0.1 \%$ and $30 \%$, respectively.

The compressive strength was maximum with the superplasticizer content of $0.1 \%$ and the slag powder content of $30 \%$, indicating that the superplasticizer and the slag powder had a good effect on the later strength at $20^{\circ} \mathrm{C}$. The compressive strength at $40{ }^{\circ} \mathrm{C}$ first increased and then decreased with the increase of the superplasticizer and slag powder, and the maximum was reached when the content of the superplasticizer and slag powder was $0.1 \%$ and $30 \%$, respectively.

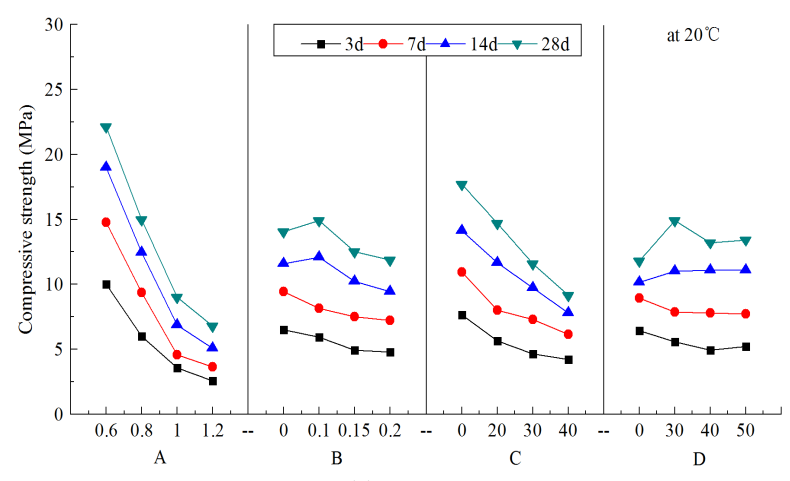

(a) $20{ }^{\circ} \mathrm{C}$

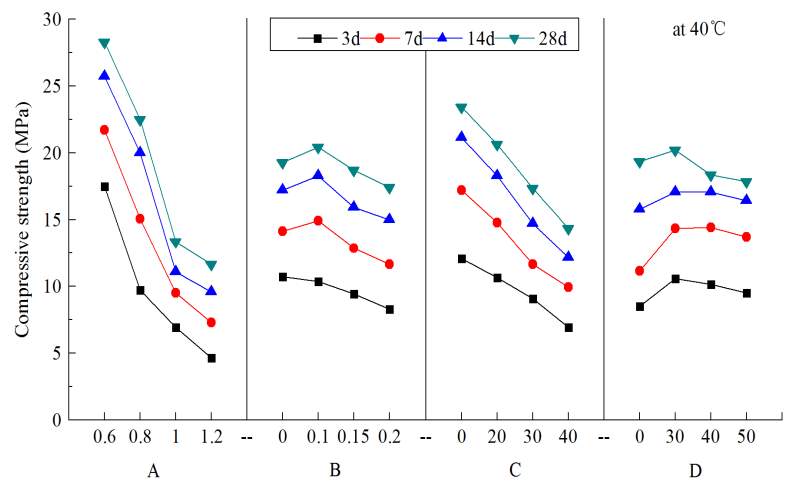

(b) $40{ }^{\circ} \mathrm{C}$

Fig. 6. Curves of compressive strength at different temperatures varying with factors, W-C (A), superplasticizer content (B/\%), fly ash content $(\mathrm{C} / \%)$, slag powder content (D/\%).

\subsection{Optimal analysis}

In the matrix analysis method, there are four matrices that need to be calculated. They are evaluation index matrix $M$, factor matrix $T$, level matrix $S$ and weight matrix $W$ respectively. They can be calculated as:

$W=M T S$

$T=\left[\begin{array}{cccc}T_{\mathrm{A}} & 0 & \cdots & 0 \\ 0 & T_{\mathrm{B}} & \cdots & 0 \\ \cdots & \cdots & \cdots & \cdots \\ 0 & 0 & \cdots & T_{\mathrm{D}}\end{array}\right]$ 


$$
\begin{aligned}
& T_{i}=1 / \sum_{j=1}^{4} K_{i j} \\
& S=\left[\begin{array}{c}
S_{\mathrm{A}} \\
S_{\mathrm{B}} \\
\cdots \\
S_{\mathrm{D}}
\end{array}\right] \\
& S_{i}=R_{i} / \sum_{i=1}^{4} R_{i}
\end{aligned}
$$

\begin{tabular}{|c|c|c|c|c|c|}
\hline \multirow{2}{*}{$\mathrm{T}\left({ }^{\circ} \mathrm{C}\right)$} & \multicolumn{2}{|c|}{ The setting time (min) } & \multirow{2}{*}{ Bleeding rate (\%) } & \multirow{2}{*}{ Viscosity (s) } & \multirow{2}{*}{$\begin{array}{c}\text { Compressive strength } \\
\text { (28d) (MPa) }\end{array}$} \\
\hline & Initial set & Final set & & & \\
\hline 20 & 512 & 596 & 7.9 & 40.39 & 30.5 \\
\hline 40 & 313 & 387 & 4.4 & 42.10 & 34.8 \\
\hline
\end{tabular}

Table 8. Test results of the optimal formulation.

According to the sensitivity analysis of various factors, the optimal formulation of CBGM that satisfied the conditions of short setting time, low bleeding rate, low viscosity and high compressive strength was obtained. And the combination for optimal formulations at $20^{\circ} \mathrm{C}$ and $40{ }^{\circ} \mathrm{C}$ were both $\mathrm{A} 1 / \mathrm{B} 3 / \mathrm{C} 1 / \mathrm{D} 2$ through the matrix analysis method. This combination was not in the orthogonal experimental design scheme, so supplementary experiment at this optimal formulation needed to be carried out to verify it. The results of new experiments are shown in Table 8.

The supplementary experiments results were slightly better than the orthogonal experiments'. The new results indicated the grout at optimal formulation possessing better properties. Compared with the results of 16 groups of orthogonal experiments, the experimental results obtained by the matrix analysis method optimized by the matching scheme were better. The 28-day compressive strength of the optimized scheme was $12.1 \%$ higher than that of the second orthogonal experiment at $20{ }^{\circ} \mathrm{C}$. The 28 -day compressive strength of the optimized scheme was $4.5 \%$ higher than that of the first orthogonal experiment at $40^{\circ} \mathrm{C}$.

\section{Conclusions}

The superplasticizer and mineral admixtures were added to the cement grout, and the orthogonal experiment was applied to optimize the grout formulation at the temperatures $20^{\circ} \mathrm{C}$ and $40{ }^{\circ} \mathrm{C}$. Meanwhile, the range analysis was used to study the effects degree of different factors on the properties of CBGM and the matrix analysis was applied to obtain the optimal formulation of CBGM at $20^{\circ} \mathrm{C}$ and $40{ }^{\circ} \mathrm{C}$. The main conclusions are as following:

$$
M=\left[\begin{array}{cccc}
K_{\mathrm{A} 1} & 0 & \cdots & 0 \\
K_{\mathrm{A} 2} & 0 & \cdots & 0 \\
\cdots & \cdots & \cdots & 0 \\
K_{\mathrm{A} 4} & 0 & \cdots & 0 \\
0 & K_{\mathrm{B} 1} & \cdots & 0 \\
0 & K_{\mathrm{B} 2} & \cdots & 0 \\
\cdots & \cdots & \cdots & \cdots \\
0 & K_{\mathrm{B} 4} & \cdots & 0 \\
\cdots & \cdots & \cdots & \cdots \\
0 & 0 & \cdots & K_{\mathrm{D} 1} \\
0 & 0 & \cdots & K_{\mathrm{D} 2} \\
\cdots & \cdots & \cdots & \cdots \\
0 & 0 & \cdots & \mathrm{K}_{\mathrm{D} 4}
\end{array}\right]
$$

where $j$ represents the factor levels, from 1 to $4 ; i$ is the factor $\mathrm{A}, \mathrm{B}, \mathrm{C}, \mathrm{D} ; R_{i}$ is defined as the range value of factor $j$; $k_{i j}$ indicates the mean value of the corresponding indices of factor $i$ at all level $j$. The average value of the test index at the level $j$ of factor $A_{i}$ is $k_{i j}$. If the test result is the larger the better, then $K_{i j}=k_{i j}$; if the test result is the smaller the better, then $K_{i j}=1 / k_{i j}$. Through calculation, the weight of each factor and each level on the test results can be obtained, and then the best optimal scheme can be obtained according to the weight.

(1) The setting time of CBGM is largely affected by the fly ash content, in part because of the hydration reaction rate on account of dense surface layer in the microstructure. While viscosity, bleeding rate and compressive strength are mainly affected by $W / C$ ratio.

(2) The setting time of $\mathrm{CBGM}$ at $40{ }^{\circ} \mathrm{C}$ is shorter than that at $20^{\circ} \mathrm{C}$, and the bleeding rate and compressive strength of $\mathrm{CBGM}$ at $40{ }^{\circ} \mathrm{C}$ are superior than those at $20{ }^{\circ} \mathrm{C}$. Nevertheless, the viscosity varies in different ways at $20^{\circ} \mathrm{C}$ and $40{ }^{\circ} \mathrm{C}$.

(3) The optimal formulation of CBGM is: $W / C$ ratio of 0.6 , bentonite content of $0 \%$, superplasticizer content of $0.15 \%$, fly ash content of $0 \%$, and slag powder content of $30 \%$.

The optimal formulation of the grouting materials was obtained from a macro point of view. However, there was a lack of research on micro aspects. In the next step, the scanning electron microscopy will be applied to analyse the filling and interface bonding effect of the grout consolidated body sampled in the field from a microscopic perspective.

\section{Acknowledgments}

This work was financially supported by the Scientific and Technological Research Projects in Henan Province (212102310974), and the Scientific and Technological Innovation Project of China Railway Tunnel Group Co., Ltd. (H20-095)

This is an Open Access article distributed under the terms of the Creative Commons Attribution License. 


\section{References}

1. Wang, S. R., Li, N., Li, C.L., Zou, Z.S., Chang, X., "Instability mechanism analysis of pressure-arch in coal mining field under different seam dip angles”. Dyna, 90(3), 2015, pp. 279-284.

2. Liu S. H., Fu J. Y., Yang J. S., Feng H., "Numerical simulation of temperature effects on mechanical behavior of the railway tunnel in Tibet”. Journal of Civil Engineering, 24(12), 2020, pp. 3875-3883.

3. Wilhelm, J., Rybach, L., "The geothermal potential of Swiss Alpine tunnels". Geothermics, 32, 2003, pp. 557-568.

4. Zhu H. H., Yan J. X., Liang W. H., "Challenges and development prospects of ultra-long and ultra-deep mountain tunnels". Engineering, 5, 2019, pp. 384-392.

5. Zhang Y., Wan Z. J., Ma Z. Y., Gu B., Ma Y. S., "Heat transfer analysis of surrounding rocks with thermal insulation layer in high geothermal roadway". Thermal science, 23(2), 2019, pp. 777-790.

6. Farenyuk, G., "The determination of the thermal reliability criterion for building envelope structures". Technical Journal, 13(2), 2019, pp. 129-133.

7. Wang, S. R., Hagan, P., Li, Y. C., Zhang, C. G., Liu, X. L., Zou, Z. S. "Experimental study on deformation and strength characteristics of sandstone with different water contents". Journal of Engineering Science and Technology Review, 10(4), 2017, pp. 199-203.

8.Liu P., Cui S. G., Li Z. H., Xu X. F., Guo C., "Influence of surrounding rock temperature on mechanical property and pore structure of concrete for shotcrete use in a hot-dry environment of high-temperature geothermal tunnel". Construction and Building Materials, 207, 2019, pp. 329-337.

9. Wang M. N., Hu Y. P., Wang Q. L., Tian H. T., Liu D. G., “A study on strength characteristics of concrete under variable temperature curing conditions in ultra-high geothermal tunnels". Construction and Building Materials, 229, 2019, pp. 1-14.

10. Wang B., Guo X. X., Li F. H., Hu D. H., Jia Y., "Mechanical behavior of rock bolts under a high temperature environment". International Journal of Rock Mechanics and Mining Sciences, 104 2018, pp. 126-130.

11. Wang M. N., Hu Y. P., Jiang C., "Mechanical Characteristics of Cement-Based Grouting Material in High-Geothermal Tunnel". Materials, 13, 2020, pp. 1 -18.

12. Cui S. G., Liu P., Su J., "Experimental study on mechanical and microstructural properties of cement-based paste for shotcrete use in high-temperature geothermal environment". Construction and Building Materials, 174, 2018, pp. 603-612.

13. Li S. C., Sha F., Liu R. T., "Properties of cement-based grouts with high amounts of ground granulated blast-furnace slag and fly ash". Journal of Civil Engineering Materials, 29(11), 2017, pp. 1-11.
14. Sha F., Li S. C., Liu R. T., "Experimental study on performance of cement-based grouts admixed with fly ash, bentonite superplasticizer and water glass". Construction and Building Materials, 161, 2018, pp. 282-291.

15. Narmluk M., Nawa T., "Effect of fly ash on the kinetics of Portland cement hydration at different curing temperatures". Cement and Concrete Research, 41, 2011, pp. 579-589.

16. Sun J. W., Zhang Z. Q., Hou G. H., "Utilization of fly ash microsphere powder as a slag admixture of cement: Effects on early hydration and microstructure at different curing temperatures". Powder Technology, 375, 2020, pp. 262-270.

17. Wang P. M., Liu X. P., "Effect of temperature on the hydration process and strength development in blends of Portland cement and activated coal gangue or fly ash". Journal of Zhejiang UniversityScience (Applied Physics \& Engineering), 12(2), 2011, pp. 162-170.

18. Chen P., Zhang S. M., Yang H. M., Hu C., "Effects of curing temperature on rheological behaviour and compressive strength of cement containing GGBFS". Journal of Wuhan University of Technology-Mater (Sci. Ed.), 34(5), 2019, pp. 1155-1162.

19. Aziz M. A. A., Aleem S. A. E., Heikal M., "Physico-chemical and mechanical characteristics of pozzolanic cement pastes and mortars hydrated at different curing temperatures". Construction and Building Materials, 26, 2012, pp. 310-316.

20. Zhang W. Q., Zhu X. X., Xu S. X., Wang Z. Y., Li W. "Experimental study on properties of a new type of grouting material for the reinforcement of fractured seam floor". Journal of materials research and technology, 8(6), 2019, pp. 5271-5282.

21. Liu F. Q., Zheng M. L., Ye Y. S., "Formulation and properties of a newly developed powder geopolymer grouting material". Construction and Building Materials, 258, 2020, pp. 1-12.

22. Sha F., Jin Q., Liu P., "Development of effective microfine cement based grouts (EMCG) forporous and fissured strata". Construction and Building Materials, 262, 2020, pp. 1-23.

23. Zhang C., Fu J. Y., Yang J. S., Ou X. F., Ye X. T., Zhang Y., "Formulation and performance of grouting materials for underwater shield tunnel construction in karst ground". Construction and Building Materials, 187, 2018, pp. 327-338.

24. Shi J. W., Wei Z. J., Liu Q. L., "Research on optimal formulation of paste filling materials based on orthogonal experiment in coal mine”. China Safety Science Journal, 21(6), 2011, pp. 111-115.

25. Zhou Y. Z., "Matrix analysis method for orthogonal experimental design". Journal of Mathematics in Practice and Theory, 39(2), 2009, pp. 202-207. 